\title{
High-titer, serum-free production of adeno-associated virus vectors
}

by polyethyleneimine-mediated plasmid transfection in mammalian suspension cells

\section{Journal Article}

Author(s):

Hildinger, Markus; Baldi, Lucia; Stettler, Matthieu; Wurm, Florian M.

Publication date:

2007

Permanent link:

https://doi.org/10.3929/ethz-b-000066202

Rights / license:

In Copyright - Non-Commercial Use Permitted

Originally published in:

Biotechnology Letters 29(11), https://doi.org/10.1007/s10529-007-9441-3 


\title{
High-titer, serum-free production of adeno-associated virus vectors by polyethyleneimine-mediated plasmid transfection in mammalian suspension cells
}

\author{
Markus Hildinger · Lucia Baldi • \\ Matthieu Stettler · Florian M. Wurm
}

Received: 6 March 2007 / Revised: 1 June 2007 / Accepted: 5 June 2007 / Published online: 17 July 2007

(C) Springer Science+Business Media B.V. 2007

\begin{abstract}
Adeno-associated virus (AAV)-based vectors belong to the most promising gene transfer vectors in clinical studies. To provide vector for latestage clinical trials as well as for a potential commercial phase, a scalable, cGMP-compliant process is required. Nearly all vector production protocols currently approved in Phase I clinical trials rely on AAV production in adherent HEK 293 cells in the presence of serum. In this study, we present a helperand serum-free production method of AAV vectors in suspension-adapted HEK 293 cells. The method is based on plasmid transfection with $25 \mathrm{kDa}$ linear polyethyleneimine. Compared to existing methods, our system is highly scalable as cells grow in suspension, does not require animal-derived products or the use of an exogenous virus (adenovirus or baculovirus) and yields genomic titers equal to those obtained in adherent HEK 293 cells in the presence of serum. Most importantly, work load and cost could be dramatically reduced in comparison to earlier methods, when comparing the production of equivalent
\end{abstract}

M. Hildinger · F. M. Wurm

ExcellGene S.A, Route de l'ile-au-bois 1A, Monthey,

Valais 1870 , Switzerland

L. Baldi · M. Stettler · F. M. Wurm ( $\square)$

Institute of Biological Engineering and Biotechnology,

Laboratory of Cellular Biotechnology, Swiss Federal

Institute of Technology (EPFL), Lausanne 1005,

Switzerland

e-mail: florian.wurm@epfl.ch volumes of cell culture media. Thus, our protocol should appeal to both basic research laboratories and cGMP manufacturing units.

Keywords Adeno-associated virus - Gene therapy · GMP · Production · Serum-free $\cdot$ Suspension

\section{Introduction}

Recombinant adeno-associated viruses (AAV) hold much promise for human gene therapy (Samulski 2003; Mandel and Burger 2004; Li et al. 2005). In this study, we describe a cost and time effective, highly scalable, serum-free method for producing AAV preparations based on transfection of suspension adapted HEK 293 cells (Baldi et al. 2005). This technique does not require expensive, special equipment or consumables and is thus equally applicable to GMP-grade vector manufacturing as well as to bench research. Briefly, suspension-adapted HEK 293 cells, growing as single cells in defined, serum-free media, are transfected while maintained in suspension culture. Producer cells are harvested 2-3 days after transfection by a simple centrifugation step. Yields are comparable to those obtained with a standard protocol [e.g. adherent HEK 293 cells in media with $10 \%$ v/v FCS (Auricchio et al. 2001)].

Most protocols for larger-scale AAV production are based on stable cell lines (Maxwell et al. 1997; Liu et al. 2000; Gao et al. 2002; Farson et al. 2004) and/or 
viral infection (Conway et al. 1999; Booth et al. 2004; $\mathrm{Li}$ and Samulski 2005). Only few research groups have worked on AAV production in suspension cells but have pursued approaches that are different from our transfection-based protocol. For example, Farson et al. (2004) have described a process for producing AAV preparations in suspension cells without serum. Their method relies on a A549-derived stable producer cell line (which afterwards was adapted to suspension growth) and infection of that cell line with an adenoviral vector. In contrast, our method does not rely on a stable cell line; instead, all components required for AAV production are introduced into the producer cell by DNA transfection, which offers a higher degree of flexibility as the cap and rep sequences can be varied from preparation to preparation. In addition, Farson et al. created the producer cell first, and then adapted it to suspension growth.

Urabe et al. (2002) described a method for producing large quantities of AAV vectors in Sf9 (insect) cells. Sf9 cells grow in suspension, and serum is not essential for their growth. The system requires a baculovirus to introduce AAV packaging functions into the producer cells though adenoviral helper functions are not needed. Whereas this is an excellent system to produce AAV, there is the additional need of producing baculovirus. Furthermore, packaging constructs optimized for expression in mammalian cells have to be modified in order to achieve highyield production in Sf9 cells, which could become a bottleneck if one works with some of the more recently identified serotypes.

Our simple, fast and scalable protocol represents an interesting alternative to existing AAV production systems based on mammalian cell transfection and should be attractive for GMP manufacturing and bench research.

\section{Materials and methods}

Unless otherwise stated, all experiments were performed in triplicates.

\section{Plasmid constructs}

The AAV2 packaging plasmid (pRepCap2), Ad helper (pHelper) plasmid and cis vector have been described (Stratagene 2004). The plasmid sequences can be sent electronically upon request. Plasmid DNA was purified using the Giga Plasmid Preparation Kit (Qiagen GmbH, Hilden, Germany).

Vector production

\section{Standard protocol}

Our standard protocol for AAV production has been described (Auricchio et al. 2001). In short, for one AAV vector preparation, $5015-\mathrm{cm}$ dishes of subconfluent, low $(<50)$ passage HEK 293 cells (ATCC, Manassas, VA) were transfected by calcium phosphate with $2.5 \mathrm{mg}$ plasmid DNA (pHelper, pRepCap2, pAAV eGFP in the ratio 2:1:1). Medium was changed the following day, and cells were harvested 3 days after transfection and the virus isolated as previously described (Auricchio et al. 2001). We have also produced AAV virions in adherent HEK 293 cells using polyethyleneimine (PEI) as transfection reagent (and a medium change $7 \mathrm{~h}$ after transfection). Titers were similar to those obtained with calcium phosphate (data not shown).

\section{Suspension protocol}

Expansion: Prior to transfection, suspension-adapted HEK293E cells (Durocher et al. 2000) were expanded in Ex-Cell 293 HEK 293 serum-free medium (JRH Biosciences, Lenexa, Kansas, USA, "Ex-Cell" medium) with $4 \mathrm{mM} \mathrm{L-glutamine.} \mathrm{Cells} \mathrm{were} \mathrm{cultured} \mathrm{at}$ $10^{6}$ cells per ml up to $4 \times 10^{6}$ cells per ml. Splitting was done by pelleting the cells and resuspending them at the appropriate density in Ex-Cell medium. The day prior to transfection, cells were resuspended in fresh Ex-Cell medium at $10^{6}$ cells per $\mathrm{ml}$ so that they are in their growth phase at the day of transfection. Cells were maintained in square-shaped glass bottles with a screw cap (Schott Glass, Mainz, Germany) with medium equal or less than $1 / 3$ of the bottle volume and with agitation at $110 \mathrm{rpm}$ on a model orbital shaker (Muller et al. 2005). Agitation is essential for our protocol to work in order to provide cells with sufficient $\mathrm{O}_{2}$ to survive at the cell densities used; without agitation, cells will settle to the ground of the glass bottle and die.

Transfection: For transfection, cells were pelleted, washed once with phosphate buffered saline (PBS), and resuspended at $2 \times 10^{6}$ cells per $\mathrm{ml}$ in RPMI 1640 with $25 \mathrm{mM}$ HEPES (pH 7.1) and $4 \mathrm{mM} \mathrm{L-glutamine}$ 
(BioWhittaker Europe/Cambrex, Verviers, Belgium) and 1\% Pluronic F68. The transfection cocktail was prepared as follows (quantities are per $\mathrm{ml}$ of resuspended cells): $7.5 \mu \mathrm{l}$ of a $1 \mu \mathrm{g} / \mu \mathrm{l}$ solution of $25 \mathrm{kDa}$ polyethyleneimine (PEI; Polysciences, Eppelheim, Germany; pH7) was added to $42.5 \mu 1150 \mathrm{mM} \mathrm{NaCl}$ (pH7). Separately, $2.5 \mu \mathrm{g}$ of DNA was dissolved in $50 \mu 150 \mathrm{mM} \mathrm{NaCl}(\mathrm{pH} 7)$. Then, the DNA was added to the PEI solution and resuspended by pipetting up and down. The complex was incubated for about $8 \mathrm{~min}$ at room temperature, and then added to the cells. (The complex should be added after 6-10 min incubation; earlier or later times decrease transfection efficacy by a factor of up to 2-unpublished data.) In the standard protocol, the three plasmids pHelper, pRepCap2, pAAV eGFP were transfected in a ratio of 2:1:1. For small-scale preparations (up to $5 \mathrm{ml}$ final volume), cells were grown in 6-well plates under agitation at $200 \mathrm{rpm}$ at $37^{\circ} \mathrm{C}$. For large-scale preparations, the cells-upon addition of the transfection cocktail-were transferred into a round-shaped Schott glass bottle with a screw cap and shaken at $120 \mathrm{rpm}$ on a orbital shaker at $37^{\circ} \mathrm{C}$. $\mathrm{A} \mathrm{CO}_{2}$ atmosphere is optional. Four hours after transfection, an equal volume of Ex-Cell medium was added (i.e., $1 \mathrm{ml}$ Ex-Cell medium for each ml RPMI medium.) In case of larger scale transfections, the cells were transferred into a squareshaped Schott glass bottle (up to $300 \mathrm{ml}$ into one 11 bottle.) The cells were then propagated for 48 or $72 \mathrm{~h}$ under agitation and then harvested by centrifugation. In addition to Ex-Cell medium, we also evaluated Pro-293s-CDM in our small scale experiments (BioWhittaker, Cambrex BioSciences, Walkerville, MD, USA); yet, given that it resulted in lower titers compared to Ex-Cell, we performed all large scale experiments with Ex-Cell medium.

\section{Vector characterization}

\section{Genomic titer}

The genomic titer was determined via Quantitative Real-Time PCR using the QuantiTect SYBR Green PCR Kit (Qiagen GmbH, Germany) and an ABI 7900 RealTime System (Applied Biosystems) according to the manufacturers' instructions. Prior to the RealTime PCR, recombinant vector preparation was pretreated with DNase I and RNase A (Fermentas
$\mathrm{GmbH}$, Germany). The DNase and RNase were then heat-inactivated for $30 \mathrm{~min}$ at $65^{\circ} \mathrm{C}$. After that, the recombinant vector preparations were treated with $50 \mu \mathrm{g}$ proteinase $\mathrm{K}$ (Fermentas $\mathrm{GmbH}$, Germany) at $55^{\circ} \mathrm{C}$ for $30 \mathrm{~min}$ and $60^{\circ} \mathrm{C}$ for $30 \mathrm{~min}$, and the proteinase $\mathrm{K}$ was subsequently heat-inactivated for $20 \mathrm{~min}$ at $95^{\circ} \mathrm{C}$.

\section{Functional titer}

The functional titer was determined either by serial dilution or by fluorometry. For the serial dilutions, HEK 293 cells that had been transfected with pHelper were infected with 1:5 dilutions of AAV eGFP, and the read-out was done using a fluorescence microscope. For the fluorimetric assay, HEK 293 cells that had been transfected with pHelper were infected with AAV eGFP. The cells were then lysed by two rounds of freeze-and-thaw, and eGFP fluorescence was measured using a CytoFluor 4000 (MTX Lab Systems).

\section{Results}

Influence of medium composition on AAV yields

Medium composition is an essential factor in AAV production. It influences the cell cycle, apoptosis, promoter activities and many other factors that play a role in the AAV life cycle. Thus, we tested three different media (RPMI, Ex-Cell, Pro-293s) for cultivating transfected suspension-adapted HEK 293 cells in the production phase ("production medium"). We also analyzed combinations of those media, with and without fetal calf serum (see Materials and Methods). The results are summarized in Fig. 1 for AAV2 (similar results were obtained with AAV5).

As expected, AAV yields were the lowest in RPMI as it is the most basic medium tested. Using the defined media Pro-293s and Ex-Cell increased virus yield by $50 \%$ and $100 \%$, respectively. Yet, to our surprise, the best results were obtained with a $1: 1$ mixture of RPMI and Ex-Cell (approximately 5-fold increase in virus yield over RPMI alone.) The composition of Ex-Cell is not published; however, we assume it to contain factors with a negative effect on AAV production-while promoting HEK 293 cell growth and viability; for example, we have observed 


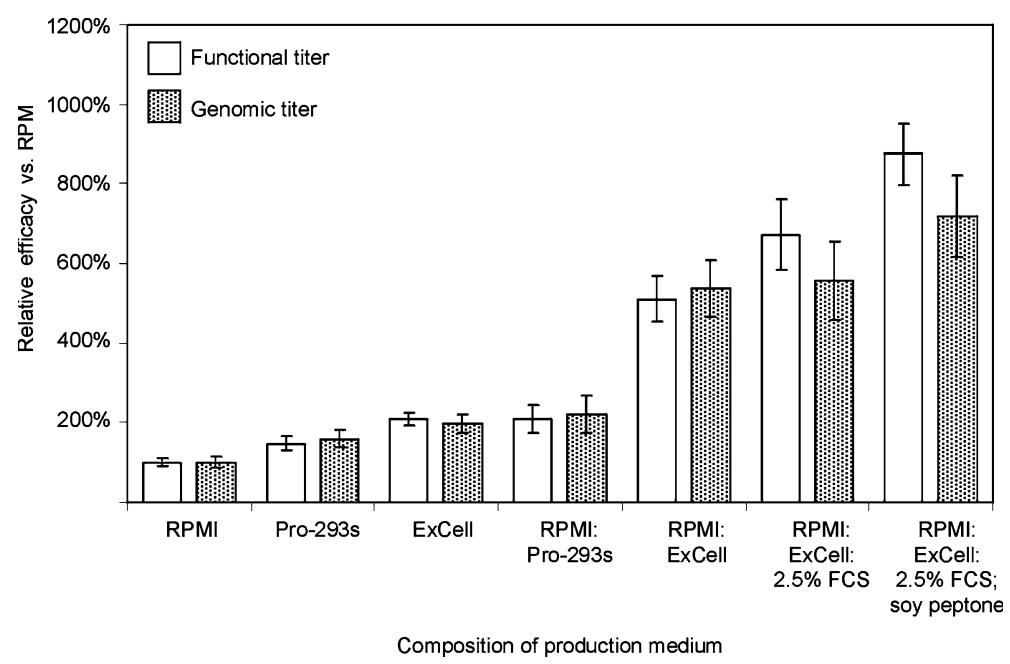

Fig. 1 For each medium to be tested, $4 \times 10^{6}$ cells were transfected in triplicates (4 $\mathrm{ml}$ final volume) as described in Materials and Methods using plasmids pHelper, pRepCap2, pAAV eGFP in a ratio of $2: 1 ; 1$. About $4 \mathrm{~h}$ after transfection, cells were resuspended in the medium to be analyzed. Three days later, cells were harvested and virus isolated. Functional titer was determined by infecting adherent HEK 293 cells that have been transfected with pHelper. Three days after infection,

a negative impact of certain yeast peptones on AAV yields when added to the medium (unpublished data). The addition of serum during transfection had only a modest effect on AAV production: the functional titers increased by approximately 30\%, the genomic titers were not significantly different. Thus, serum has no influence on the total number of AAV particles, but might have a positive effect on virus particle stability. The addition of soy peptones the day after transfection in the presence of serum resulted in an additional $30 \%$ increase in yield.

As for cell survival in the different production media, we did not see any significant differences; however, the cell number at time of harvest was about $30 \%$ lower in pure RPMI compared to the other media formulations used (cells normally do not divide within the first 36 hours after transfection).

Influence of PEI:DNA-to-cell ratio and packaging plasmids on AAV yields

We next analyzed the optimal ratio of PEI:DNA-to cell ratio for the transfection as well as some alternative packaging plasmids. The optimal PEI:DNA ratio of 3:1 infected cells were lysed by two rounds of freeze-and-thaw, and the amount of GFP in the lysate was quantified using a Cytofluor. Genomic titer was determined by RealTime PCR. Data are shown as mean values relative to RPMI as production medium. The absolute titers in RPMI were $1.8 \times 10^{12}$ (genomic) and $3.3 \times 10^{11}$ (functional) per liter of culture medium, respectively

has already been published (Baldi et al. 2005), and all experiments were performed using that ratio.

In a first experiment, we compared virus yields by leaving the amount of PEI and DNA constant and varied the cell density between $5 \times 10^{5}$ cells per ml and $8 \times 10^{6}$ cells per ml (see Fig. $2 \mathrm{~A}$ ). The optimal cell density for AAV production-according to our data-is $2 \times 10^{6}$ per $\mathrm{ml}$. The decreased production at lower cell densities is most likely due to increased PEI toxicity (Florea et al. 2002) as there are now more PEI molecules per cell; at higher cell densities, production is decreased due to decreased transfection efficacy: Using pAAV eGFP alone one can clearly observe normal transfection efficacies at lower cell densities (yet, cell viability is decreased) and decreased transfection efficacies (lower eGFP expression) at higher cell densities (data not shown).

In a second experiment, we analyzed the influence of the amount of PEI:DNA on virus yields, leaving the PEI:DNA ratio constant at 3:1 (see Fig. 2B) $1.25 \mu \mathrm{g} \mathrm{DNA} / \mathrm{ml}$ was the optimal ratio. Halving the amount of DNA decreased the virus yield by over $50 \%$; on the other hand, increasing the amount of DNA had only a slightly positive effect $(22 \%)$ on the functional titer. However, this effect was additive to 

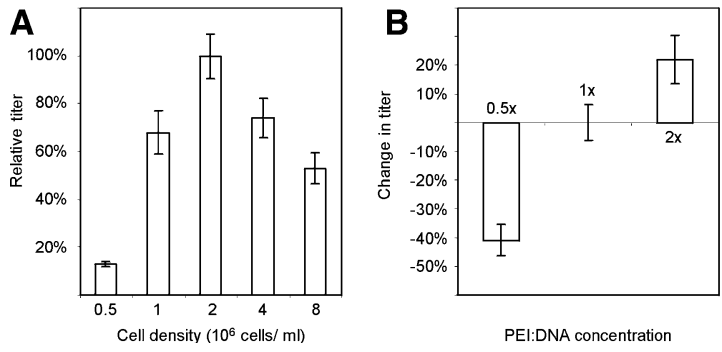

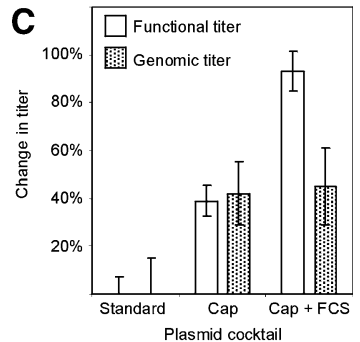

Fig. 2 For each condition tested, cells were transfected in triplicates as described in Materials and Methods in a total volume of $4 \mathrm{ml}$. Three days post-transfection, cells were harvested and virus isolated. Functional titer was determined by infecting adherent HEK 293 cells that have been transfected with pHelper. Three days after infection, infected cells were lysed by two rounds of freeze-and-thaw, and the amount of GFP in the lysate was quantified using a Cytofluor. (A) Data are shown as mean values relative to the expression obtained at a cell density of $2 \times 10^{6}$ cells $/ \mathrm{ml}$ at the time of transfection. (B) Data are shown as average percentage change in GFP

the serum effect, i.e., using $2.5 \mu \mathrm{g} \mathrm{DNA} / \mathrm{ml}$ the amount of DNA in the presence of serum resulted in an overall titer increase of about $50 \%$. Yet, even with the added serum effect, it is more economical to leave the DNA concentration at $1.25 \mu \mathrm{g} / \mathrm{ml}$ and double the production volume, which-given the scalability of the system-does not significantly increase the work load.

In a third experiment, we evaluated a different DNA cocktail for AAV production. Capsid formation is the rate-limiting step in AAV production (Vincent et al. 1997). Thus, we decided to execute a quadruple transfection of pAAV2 eGFP, pRepCap2, pHelper and pCMV Cap in a ratio of 1:1:1:1 (see Materials and Methods), where the Cap ORF is expressed under the control of the CMV promoter. The results are depicted in Fig. 2C. Interestingly, titers increased by roughly $40 \%$ through the addition of pCMV Cap. In the presence of serum, the functional titer nearly doubled, most likely due to further increased Cap expression (the CMV promoter is serum responsive (Brightwell et al. 1997) and unpublished data).

Effect of harvest time on AAV yields and infectivity

As an additional factor in AAV production, we evaluated the effect of harvest timing on AAV yields, i.e. the timing between transfection and discontinuation of the cell culture. Our hypothesis was that expression with GFP expression at $1.25 \mu \mathrm{g} \mathrm{DNA} / \mathrm{ml}(1 \times)$ as reference $(0.5 \times: 0.625 \mu \mathrm{g} / \mathrm{ml} ; 2 \times: 2.5 \mu \mathrm{g} / \mathrm{ml})$. (C) Data are shown as average percentage increase in GFP expression relative to the expression obtained with the standard protocol (plasmids pHelper, pRepCap2, pAAV eGFP in a ratio of 2:1:1; growth in RPMI:Ex-Cell medium; no serum added). The absolute functional titers were $4.1 \times 10^{11}(2 \mathrm{a} ; 100 \%)$, $3.5 \times 10^{11}(2 \mathrm{~b} ; 1 \times)$ and $3.7 \times 10^{11}(2 \mathrm{c}$; standard with a genomic titer of $2.1 \times 10^{12}$ ) per liter of culture medium, respectively

genomic titers would increase with time (as more particles accumulate in the nucleus) but functional titers could decline due to "storage" in the nucleus. Thus, we compared an AAV harvest 2 days after transfection with an AAV harvest three days after transfection (Fig. 3A). The data confirmed our initial hypothesis: whereas 3 days of production increased the genomic titer by approximately $100 \%$ compared to 2 days of production, functional titers were approximately $30 \%$ higher when the cells were harvested after 2 days. In other words, whereas the ratio of genomic to infectious particles was approximately 10:1 after 2 days of production, it deteriorated to $26: 1$ after 3 days of production (data not shown). Thus, for optimal yields of infectious particles, a production period of two days should be preferred over 3 days.

We then compared the day-two harvest with $2.5 \mu \mathrm{g}$ $\mathrm{DNA} / \mathrm{ml}$ and transfection in the presence of $5 \%(\mathrm{v} / \mathrm{v})$ FCS (2.5\% final concentration) with the basic protocol (1.25 $\mu \mathrm{g} \mathrm{DNA} / \mathrm{ml}$; no FCS; day-3 harvest; Fig. 3B). With this combination, genomic titers were not statistically different but the functional titer was $60 \%$ higher in the preparation with 2 days of growth.

We explain this observation with the fact that a higher quantity of starting DNA becomes more crucial if the cells grow for a shorter period of time; and whereas there is some toxicity when using higher amounts of PEI:DNA, the presence of serum seems to counteract. (We also performed an experiment with $2.5 \mu \mathrm{g} \mathrm{DNA} / \mathrm{ml}$, where the serum was added after 


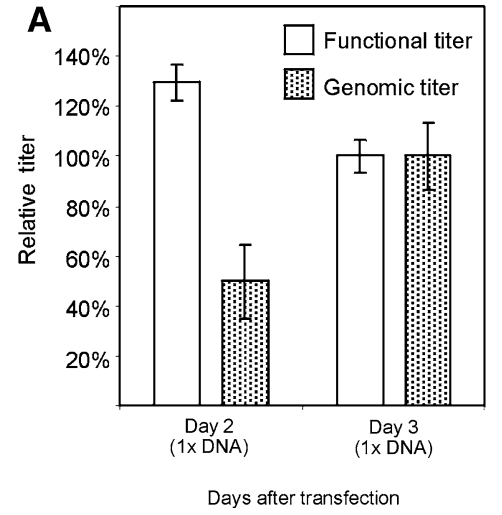

Fig. 3 For each condition tested, cells were transfected in triplicates as described in Materials and Methods in a total volume of $4 \mathrm{ml}$ using plasmids pHelper, pRepCap2, pAAV eGFP in a ratio of $2: 1: 1$. Two or three days post-transfection, cells were harvested and virus isolated. Genomic titer was determined by RealTime PCR as described in Materials and Methods. Functional titer was determined by infecting adherent HEK 293 cells that have been transfected with pHelper; three days after infection, infected cells were lysed by two rounds of freeze-and-thaw, and the amount of GFP in the lysate was

transfection; in that instance-independent of the growth period-we did not observe a positive effect of the serum.)

Comparison of AAV production in adherent cells (10\% v/v FCS; calcium phosphate transfection) versus suspension cells (serum-free; PEI transfection)

After having established an optimized protocol for AAV production in suspension-adapated HEK 293 cells without the use of animal-derived products, such as serum or trypsin, we compared the yield to those obtained with the traditional protocol based on calcium phosphate mediated transfection of adherent HEK 293 cells in DMEM with 10\%(v/v) FCS (see Materials and Methods and Auricchio et al. 2001). In order to compare the two methods, we used the medium as the common denominator, i.e., 11 of medium for the suspension culture and 11 of medium for the adherent culture, which corresponds to 50 $15-\mathrm{cm}$ dishes with $20 \mathrm{ml}$ of medium each. However, we used twice as much DNA for the calcium phosphate transfection of adherent HEK 293 cells. The results are summarized in Table 1 .

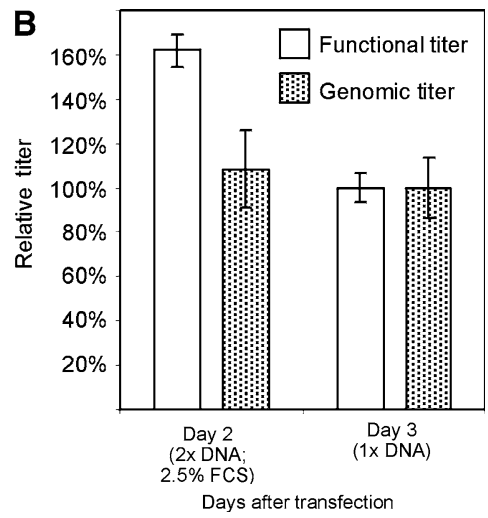

quantified using a Cytofluor. Data are shown for our standard protocol (plasmids pHelper, pRepCap2, pAAV eGFP in a ratio of 2:1:1; growth in RPMI:Ex-Cell medium). Abbreviations: Day 2 (Harvest at day 2); day 3 (Harvest at day 3), $1 \times$ DNA (1.25 $\mu \mathrm{g}$ DNA/ml final concentration); $2 \times$ DNA $(2.5 \mu \mathrm{g}$ DNA/ $\mathrm{ml}$ final concentration); $2.5 \%$ FCS $(5 \% \mathrm{v} / \mathrm{v}$ FCS added during transfection, i.e., $2.5 \% \mathrm{v} / \mathrm{v}$ FCS final concentration). The data for $1 \times$ DNA and harvest at day 3 were set to $100 \%$ (with a functional titer of $3.5 \times 10^{11}$ and a genomic titer of $9.1 \times 10^{12}$ per liter of culture medium)

Our data indicate that the virus yields as well as infectivity are comparable in both systems. If one uses the amount of DNA as the common denominator, yields per mg of transfected DNA would be twice as high in the suspension system compared to the adherent system. Furthermore, yields for AAV2/5 vectors are higher than those for AAV2/2 vectorsindependent of the system used. Given that both systems result in similar yields, the suspension system should be the method of choice given that it does not require animal-derived products, saves time and cost and can be easily scaled up or adapted to cGMP production.

\section{Discussion}

\section{Summary of key findings}

In this study, we presented a helper virus-free production method for AAV vectors in suspension-adapted HEK 293 cells without the use of animal-derived products, such as serum or trypsin. The method is based on plasmid transfection with $25 \mathrm{kDa}$ linear polyethyleneimine (Baldi et al. 2005). Yields obtained with 
Table 1 Comparison of adherent and suspension AAV production methods

\begin{tabular}{|c|c|c|c|c|c|}
\hline Method & Serotype & Transgene & Scale & $\begin{array}{l}\text { Genomic } \\
\text { titer }^{(a)}\end{array}$ & $\begin{array}{l}\text { Functional } \\
\text { titer }^{\text {(a) }}\end{array}$ \\
\hline \multirow[t]{5}{*}{$\begin{array}{l}\text { Calcium phosphate transfection of adherent HEK } 293 \text { cells in } \\
\text { DMEM with } 10 \% \text { FCS }\end{array}$} & \multirow[t]{3}{*}{ AAV2 } & eGFP & $\begin{array}{c}5015-\mathrm{cm} \\
\text { plates }\end{array}$ & $6.1 \times 10^{12}$ & $2.3 \times 10^{11}$ \\
\hline & & e GFP & $\begin{array}{l}5015-\mathrm{cm} \\
\text { plates }\end{array}$ & $1.1 \times 10^{13}$ & $3.5 \times 10^{11}$ \\
\hline & & Luciferase & $\begin{array}{l}5012-\mathrm{cm} \\
\text { plates }\end{array}$ & $4.8 \times 10^{12}$ & $\mathrm{n} / \mathrm{a}$ \\
\hline & \multirow[t]{2}{*}{ AAV5 } & eGFP & $\begin{array}{l}5015-\mathrm{cm} \\
\text { plates }\end{array}$ & $1.3 \times 10^{13}$ & $3.2 \times 10^{9}$ \\
\hline & & eGFP & $\begin{array}{l}5015-\mathrm{cm} \\
\text { plates }\end{array}$ & $1.9 \times 10^{13}$ & $3.6 \times 10^{9}$ \\
\hline \multirow{5}{*}{$\begin{array}{l}\text { PEI transfection of suspension-adapted HEK } 293 \text { cells w/o } \\
\text { animal-derived products }\end{array}$} & \multirow[t]{3}{*}{ AAV2 } & eGFP & $300 \mathrm{ml}$ & $8.7 \times 10^{12}$ & $3.1 \times 10^{11}$ \\
\hline & & eGFP & $900 \mathrm{ml}$ & $1.1 \times 10^{13}$ & $5.0 \times 10^{11}$ \\
\hline & & Luciferase & $900 \mathrm{ml}$ & $3.4 \times 10^{12}$ & $\mathrm{n} / \mathrm{a}$ \\
\hline & \multirow[t]{2}{*}{ AAV5 } & eGFP & $300 \mathrm{ml}$ & $1.2 \times 10^{13}$ & $4.1 \times 10^{9}$ \\
\hline & & eGFP & $900 \mathrm{ml}$ & $1.6 \times 10^{13}$ & $3.7 \times 10^{9}$ \\
\hline
\end{tabular}

${ }^{\text {a }}$ Titers are shown as titer per liter of culture medium. Genomic titers were determined by RealTime PCR, functional titers by serial dilution as described in Materials and Methods

this system are comparable to those obtained with traditional production methods based on calcium phosphate mediated transfection of adherent HEK 293 cells in the presence of serum. The most important single factor for AAV yields in our system was the medium composition with a more than 5-fold impact on AAV titers. Increasing Cap ORF expression was the second most important lever (approximately factor 2 in the presence of serum). Cap expression is a ratelimiting step in AAV production (Vincent et al. 1997) and our data confirm these findings. The addition of serum alone had no major impact on yields, and its positive effect is most likely due to a dampening of PEI-toxicity during the transfection phase (Florea et al. 2002). Furthermore, cells should be harvested two days after transfection: Whereas the genomic titer is approximately $50 \%$ lower compared to a day three harvest, this effect is offset by a higher infectivity of the virus particles harvested at day two-leading to an overall efficacy increase of $30 \%$.

Advantages of our protocol

Our AAV production protocol has several advantages over traditional HEK 293-based AAV production (see Table 2):
With our method, one can achieve-at the same time and without loss of AAV yield-scalability (suspension culture), GMP compliance/enablement (production without animal-derived products; no use of viruses in AAV production) and savings in terms of time, (material) cost and labor: As adherent HEK 293 cells are expanded by trypsination and seeding of cells on a two-dimensional surface (e.g., tissueculture flask), expansion, transfection and growth of adherent cells requires more time and labor cost compared to suspension cells. With suspension cells-independent of the scale-cells are propagated by determining cell density and resuspending the appropriate number of "old" cells in fresh medium. Moreover, we have grown the HEK 293 suspension cells in reusable glass bottles, whereas adherent cells require specially treated and expensive plastic surfaces to grow. Overall, material cost are about $40 \%$ lower and producing AAV in suspension-adapted HEK 293 cells takes only one fifth of the time compared to adherent HEK 293 culture.

Thus our protocol should appeal to both the basic research lab that wants to produce large quantities of AAV fast and cost effective, and industrial manufacturing units focusing on cGMP-compliant AAV production. 
Table 2 Protocol flowchart and cost estimation

\begin{tabular}{|c|c|c|c|c|c|c|}
\hline & \multicolumn{3}{|c|}{ Adherent HEK 293 cells } & \multicolumn{3}{|c|}{ Suspension-adapted HEK 293 cells } \\
\hline & Activity & Time & Cost (\$) & Activity & Time & Cost (\$) \\
\hline $\begin{array}{l}\text { Preparing cells for } \\
\text { transfection }\end{array}$ & $\begin{array}{l}\text { Splitting } 1015-\mathrm{cm} \text { plates } \\
\text { to } 30 \text { plates, and } 30 \text { plates } \\
\text { to } 60 \text { plates }(1)\end{array}$ & $120 \min ^{(2)}$ & $160^{(8)}$ & $\begin{array}{l}\text { Two cell splits with cell } \\
\text { counting, centrifugation } \\
\text { and cell resuspension }\end{array}$ & $30 \min ^{(5)}$ & $130^{(9)}$ \\
\hline & $\begin{array}{l}\text { Calcium phosphate } \\
\text { transfection with } \\
\text {-Medium change } \\
\text {-Transfection }\end{array}$ & $\begin{array}{l}100 \min ^{(3)} \\
50 \min ^{(4)}\end{array}$ & $\begin{array}{c}60 \\
25^{(10)}\end{array}$ & $\begin{array}{l}\text { PEI transfection including } \\
\text {-Medium change } \\
\text {-Transfection }\end{array}$ & $\begin{array}{l}15 \min ^{(5)} \\
20 \min ^{(6)}\end{array}$ & $\begin{array}{l}7^{(11)} \\
13^{(10)}\end{array}$ \\
\hline & $\begin{array}{l}\text { Medium change the day } \\
\text { after transfection }\end{array}$ & $100 \min ^{(3)}$ & 60 & $\begin{array}{l}\text { Addition of medium } 4 \\
\text { hours after transfection }\end{array}$ & $10 \mathrm{~min}$ & 30 \\
\hline & $\begin{array}{l}\text { Cell scraping and } \\
\text { centrifugation }\end{array}$ & $110 \min ^{(7)}$ & & Centrifugation & $10 \mathrm{~min}$ & \\
\hline Cell harvest & & $\begin{array}{l}480 \text { min } \\
\text { (8 hours) }\end{array}$ & $\$ 305$ & & $\begin{array}{l}85 \text { min } \\
\text { ( 1.5 hours })\end{array}$ & $\$ 180$ \\
\hline
\end{tabular}

Numbers for calcium phosphate transfection of $5015-\mathrm{cm}$ tissue culture plates of adherent HEK 293 cells versus PEI transfection of 11 (final volume) of suspension-adapted HEK 293 cells

(1) 50 plates for transfection; 10 plates to continue culture

(2) Assuming 3 min per plate; 40 plates to split

(3) Assuming 2 min per plate

(4) Assuming $1 \mathrm{~min}$ per plate

(5) Assuming $15 \mathrm{~min}$ for cell counting, centrifugation and resuspension

(6) Assuming one transfection cocktail and $500 \mathrm{ml}$ volume transfection volume

(7) Assuming 2 min for scraping and $10 \mathrm{~min}$ for centrifugation

(8) 21 of DMEM with 10\% FCS (US\$60); $10015-\mathrm{cm}$ tissue culture pates (US\$100)

(9) 21 of Ex-Cell medium (US\$120); US\$10 for glass bottles (recycling)

(10) US\$75 for $10 \mathrm{mg}$ DNA (Qiagen Plasmid Giga Kit)

(11) US\$7 for 0.51 RPMI $25 \mathrm{mM}$ HEPES

Acknowledgement This work was financially supported by a KTI-grant obtained from the Swiss government.

\section{References}

Auricchio A, Hildinger M, O'Connor E, Gao GP, Wilson JM (2001) Isolation of highly infectious and pure adenoassociated virus type 2 vectors with a single-step gravityflow column. Hum Gene Ther 12(1):71-76
Baldi L, Muller N, Picasso S, Jacquet R, Girard P, Thanh HP, Derow E, Wurm FM (2005) Transient gene expression in suspension HEK-293 cells: application to large-scale protein production. Biotechnol Prog 21(1):148-153

Booth MJ, Mistry A, Li X, Thrasher A, Coffin RS (2004) Transfection-free and scalable recombinant AAV vector production using HSV/AAV hybrids. Gene Ther 11(10):829-837

Brightwell G, Poirier V, Cole E, Ivins S, Brown KW (1997) Serum-dependent and cell cycle-dependent expression 
from a cytomegalovirus-based mammalian expression vector. Gene 194(1):115-123

Conway JE, Rhys CM, Zolotukhin I, Zolotukhin S, Muzyczka N, Hayward GS, Byrne BJ (1999) High-titer recombinant adeno-associated virus production utilizing a recombinant herpes simplex virus type I vector expressing AAV-2 Rep and Cap. Gene Ther 6(6):986-993

Durocher Y, Perret S, Thibaudeau E, Gaumond MH, Kamen A, Stocco R, Abramovitz M (2000) A reporter gene assay for high-throughput screening of G-protein-coupled receptors stably or transiently expressed in HEK293 EBNA cells grown in suspension culture. Anal Biochem 284(2):316-326

Farson D, Harding TC, Tao L, Liu J, Powell S, Vimal V, Yendluri S, Koprivnikar K, Ho K, Twitty C, Husak P, Lin A, Snyder RO, Donahue BA (2004) Development and characterization of a cell line for large-scale, serum-free production of recombinant adeno-associated viral vectors. J Gene Med 6(12):1369-1381

Florea BI, Meaney C, Junginger HE, Borchard G (2002) Transfection efficiency and toxicity of polyethylenimine in differentiated Calu- 3 and nondifferentiated COS-1 cell cultures. AAPS PharmSci 4(3):E12

Gao GP, Lu F, Sanmiguel JC, Tran PT, Abbas Z, Lynd KS, Marsh J, Spinner NB, Wilson JM (2002) Rep/Cap gene amplification and high-yield production of AAV in an A549 cell line expressing Rep/Cap. Mol Ther 5(5 Pt 1): 644-649

Li C, Samulski RJ (2005) Serotype-specific replicating AAV helper constructs increase recombinant AAV type 2 vector production. Virology 335(1):10-21
Li C, Bowles DE, van Dyke T, Samulski RJ (2005) Adenoassociated virus vectors: potential applications for cancer gene therapy. Cancer Gene Ther

Liu X, Voulgaropoulou F, Chen R, Johnson PR, Clark KR (2000) Selective Rep-Cap gene amplification as a mechanism for high-titer recombinant AAV production from stable cell lines. Mol Ther 2(4):394-403

Mandel RJ, Burger C (2004) Clinical trials in neurological disorders using AAV vectors: promises and challenges. Curr Opin Mol Ther 6(5):482-490

Maxwell F, Harrison GS, Maxwell IH (1997) Improved production of recombinant AAV by transient transfection of NB324K cells using electroporation. J Virol Methods 63(1-2):129-136

Muller N, Girard P, Hacker DL, Jordan M, Wurm FM (2005) Orbital shaker technology for the cultivation of mammalian cells in suspension. Biotechnol Bioeng 89(4):400-406

Samulski RJ (2003) AAV vectors, the future workhorse of human gene therapy. Ernst Schering Res Found Workshop (43):25-40

Stratagene (2004) AAV Helper-Free System

Urabe M, Ding C, Kotin RM (2002) Insect cells as a factory to produce adeno-associated virus type 2 vectors. Hum Gene Ther 13(16): 1935-1943

Vincent KA, Piraino ST, Wadsworth SC (1997) Analysis of recombinant adeno-associated virus packaging and requirements for rep and cap gene products. J Virol 71(3):1897-1905 